\title{
Deconstrucció i reflexió (auto)biogràfica des d'una experiència docent a l'assignatura de Rol i identitat del Treball Social
}

\author{
(Auto) biographical reflection and deconstruction in the context of the \\ teaching-learning process developed in the course Role and Identity in \\ Social Work
}

\section{Toni Sangrà Boladeres, Jose Antonio López Rodríguez, Silvia Iannitelli Muscolo, Rosa Maria Alemany Monleon}

\author{
Departament de Treball Social / Facultat d'Educació \\ Universitat de Barcelona \\ Passeig de la Vall d'Hebron, 171 Edifici Llevant, $3^{\text {a }}$ planta, 08035, Barcelona \\ tonisangra@ub.edu tonilopez@ub.edu siannitelli@ub.edu \\ roalemany@ub.edu
}

\begin{abstract}
Resum
El text que presentem està relacionat amb l'experiència educativa i d'aprendre que anem desenvolupant en una assignatura obligatòria de quart curs del Grau de Treball Social anomenada Rol i identitat del Treball Social. Des del punt de vista pedagògic convidem a l'estudiant a reflexionar sobre el seu propi procés d'aprenentatge a partir de la deconstrucció de la seva autobiografia. Com a professors procurem acostar-nos a l'ensenyança amb metodologies educatives fomentin un aprenentatge heteràrquic entre estudiants i docents basat en el respecte dels sabers acadèmics i de la vida quotidiana. Pensem, que en l'actual context social i educatiu, els docents tenim el repte d'obrir les possibilitats pedagògiques a través d'altres formats de transmissió del coneixement en l'ensenyament del Treball Social, i així fomentar i estimular en els estudiants la participació (com a subjectes proactius), el pensament complex, l'acció transformadora i la transdisciplinarietat dels sabers.
\end{abstract}

Aquesta proposta també s'emmarca en un projecte d'innovació docent que pretén reorientar la transmissió del coneixement a partir d'estratègies narratives. La incorporació d'aquesta experiència en el projecte comporta un aprenentatge col-lectiu i co-construit amb altres assignatures i professors que permeten ampliar les perspectives epistemològiques i les expectatives d'aprenentatge sobre les que partim.

En aquest sentit, aquest article té l'objectiu de fonamentar, explicar i reflexionar al voltant del context de l'experiència, i alhora valorar la metodologia aplicada i les accions que s'han portat a terme a partir dels resultats obtinguts.

Paraules clau: Autobiografia, Deconstrucció epistemològica, Treball Social, Aprenentatge autònom, Aprenentatge col·laboratiu.

\begin{abstract}
In the following paper we present the teaching-learning experience developed in the fourth year of the degree in Social Work in the compulsory course Role and Identity in Social Work. From the pedagogical point of view, we invite our students to reflect on their own learning process through the deconstruction of their autobiography. We focus on methodologies that promote and encourage a heterarchical learning process between students and teachers based on the respect for academic knowledge and everyday life. We believe that in the current social and educational context, teachers have the challenge to open pedagogical possibilities to other formats of transmission of knowledge in the teaching of Social Work, thus encouraging and stimulating student participation (as proactive subjects), complex thinking, transformative action and the transdisciplinarity of knowledge.
\end{abstract}


This proposal is also part of a teaching innovation project that aims to reorient the transmission of knowledge based on narrative strategies. The incorporation of this reflective approach into the project translates into a collective and co-built learning experience which involves other subjects and teachers, thus allowing us to expand the epistemological perspectives and learning expectations.

In this sense, this article aims to explain and reflect on this teaching-learning experience, and, at the same time, assess the methodology that has been used and the actions that have been carried out based on the results.

Key words: Autobiography, Epistemological deconstruction, Social Work, Autonomous learning, Collaborative learning.

\section{Introducció}

El text que presentem és una experiència docent basada en la metodologia autobiogràfica que portem a terme un grup de professors del Grau de Treball Social de la Universitat de Barcelona. Aquesta experiència es va iniciar en el context d'una assignatura anomenada Rol i identitat del Treball Social i forma part d'un projecte d'innovació docent titulat Estratègies narratives per afavorir l'aprenentatge del pensament complex ${ }^{l}$.

Des d'un punt de vista pedagògic apostem per treballar amb la idea de convidar a l'estudiant a que pugui reflexionar entorn el seu propi procés d'aprenentatge, de manera que es pugui dotar d'instruments intel-lectuals i sensibles que li permetin desenvolupar-se personal i professionalment en una societat complexa, dinàmica i canviant.

Aquest article pretén mostrar l'experiència des de diferents dimensions. Per una banda, busca situar i explicar els contextos desencadenants que motiven al professorat implicat a portar a terme aquesta experiència. Els dos primers punts del text fan referència a aquestes qüestions de caire pedagògic $i$ epistemològic. D'altra banda, en el tercer punt es justifica l'ús de l'autobiografia en l'assignatura de Rol $i$ identitat del Treball Social i es posa en relació a les qüestions que plantegen les identitats personals i professionals en el món contemporani. Per últim, entrem ja a valorar la pròpia experiència, tenint en compte els conceptes exposats en els punts anteriors, i a mostrar alguns dels seus resultats a través de les narratives dels propis estudiants.

Igualment, en el marc del projecte d'innovació docent Estratègies narratives per afavorir l'aprenentatge del pensament complex en el que hem implicat aquesta assignatura, l'article també busca ser una revisió conceptual i una recapitulació valorativa dels quatre anys en els que hem participat i co-construït (estudiants i professors) l'assignatura en el context del projecte. En aquest sentit considerem oportú esmentar els objectius del projecte:

- Potenciar que l'estudiant redescobreixi les possibilitats biogràfiques que posseeix per pensar i compenetrar-se amb la idea de complexitat, a partir d'una mirada transversal i multidimensional de la seva realitat personal i professional.

- Permetre que l'estudiant reconegui a través de la seva pròpia autobiografia com ha anat incorporant i transformant el coneixement.

\footnotetext{
${ }^{1}$ Aquest projecte d'innovació docent es porta a terme dins del Grup d'Innovació Docent Transnet i té el suport del Programa de Recerca, Innovació i Millora de la Docència i l'Aprenentatge (RIMDA) de la Universitat de Barcelona.
} 


\section{Context inicial de la recerca i la innovació docent}

Fa aproximadament set anys, en el marc de la implementació del Pla Bolonya i en el procés de reestructuració acadèmica del pla d'estudis del Grau de Treball Social de la Universitat de Barcelona, es va dissenyar i posar en marxa l'assignatura de quart curs anomenada Rol i identitat del Treball Social. En aquell moment, l'equip docent de l'assignatura coordinat per la professora Silvia Iannitelli assumia el repte d'obrir a altres possibilitats pedagògiques l'ensenyança del Treball Social en el context del nou grau. Així, el punt de partida sobre el que es va afermar el disseny de l'assignatura van ser les conclusions elaborades per l'informe Delors i les reflexions d'Edgar Morin sobre la reorganització dels sabers.

En relació a l'informe Delors, al novembre de 1991, la UNESCO va convocar la Comissió Internacional perquè reflexionés sobre l'educació i l'aprenentatge al segle XXI. Aquesta Comissió va ser presidida per Jacques Delors i estava integrada per altres catorze personalitats del món procedents de diversos sectors culturals i professionals. La Comissió Internacional sobre l'Educació per al Segle XXI, així es va denominar, va ser establerta oficialment a principis de 1993 i el seu informe final va ser conegut al 1996, i porta per títol Educació: hi ha un tresor amagat a dins.

La Comissió va considerar que el segle XXI exigeix al sistema educatiu situar el procés d'aprenentatge en quatre pilars que va identificar de la següent manera: aprendre a conèixer; aprendre a fer; aprendre a ésser i aprendre a conviure. Segons l'informe cal entendre la educació com un tot, incorporant aquests quatre pilars, presentats i il·lustrats com les bases de l'educació: "En esa concepción deben buscar inspiración y orientación las reformas educativas, en la elaboración de los programas y en la definición de nuevas políticas pedagógicas." (Delors, 1996, p.9)

Des de la formació del Treball Social pren especial importància l'aprendre a ésser i a conviure: "¿Sería posible concebir una educación que permitiera evitar los conflictos o solucionarlos de manera pacífica, fomentando el conocimiento de los demás, de sus culturas y espiritualidad?.” (Delors, 1996, p.6)

Aquest aprenentatge a viure amb l'altre, que se'ns presenta com una exigència formativa en els nostres dies, requereix noves estratègies educatives i formes diferenciades d'abordatge. Aprendre a viure amb l'altre implica un procés d'ensenyament i aprenentatge basat en una metodologia que cal co-construir i que alhora re-valoritzi els aspectes ètics i estètics de l'educació. Això vol dir, per exemple, que des de l'educació es promogui els mitjans per a comprendre l'altre en la seva particularitat, en la seva diferència i contribuir al desenvolupament d'un món més humà i més just. Com planteja Maturana (2003), quan en un grup s'acorden determinats tipus de relacions, s'estableixen també les condicions de possibilitats perquè el context en què opera aquest grup també s'adoptin relacions diferents. Si en una escola, l'objectiu principal és la disciplina, la competitivitat i el rendiment, tot canviarà entorn d'aquest propòsit fonamental. Si una escola es preocupa principalment de formar nens que es respectin a si mateixos, que aprenguin a ser ciutadans conscients i responsables, tot canviarà al voltant d'aquests objectius.

Així, el repte de l'educació en general i de la universitat en particular no és l'acumulació de coneixement, l'aposta al nostre entendre passaria per l'exercici de la ciutadania de tots i cadascun dels seus agents (docents, estudiants, personal administratiu ...), pel compromís ètic, responsable, estètic, creatiu, cal que ens ocupem $i$ ens preocupem per les emocions.

Evidentment després de cinc segles de certeses racionals, si optem per l'educació des de l'emocionalitat necessitem un canvi profund del sistema educatiu tal com ho planteja l'informe Delors (1996). En aquest sentit també Morin (2003) apunta que quan parlem de sistema estem parlant d'organització, estem parlant de subjectes vius, (pro)actius, portadors d'una història, de manera que el canvi ha de començar per tots $\mathrm{i}$ cadascun dels que participem en l'escenari educatiu. El canvi no pot ser només metodològic, sinó que també requereix d'un canvi en l'operatòria universitària, creant condicions i potencialitats que permetin la construcció de noves formes de convivència, perquè el coneixement deixi de ser un objecte extern i es converteixi en una construcció biogràfica. 


\section{La narrativa biogràfica com a criteri epistemològic de la innovació docent}

Partim de la constatació que els grans sistemes de creences (científiques i polítiques) lligades al projecte de la modernitat han caigut en una mena de bifurcació crítica. Aquests sistemes explicatius-descriptius totalitzadors permeten justificar una visió de la història amb un projecte polític, amb un ideal tecnocientífic que ofereix una total confiança amb el progrés, el coneixement pur i la visió purament instrumental de la tècnica.

Per tant, som hereus i portadors d'una visió del món, d'una ideologia i d'un conjunt de pràctiques culturals que extreien i extreuen la majoria de metàfores mestres del pensament occidental dels segles XVI i XVII que sacralitzaven l'objectivitat, la racionalitat i el progrés. En aquestes metàfores preexistents (d'acord amb les premisses del positivisme) la perspectiva de l'observador estava situada fora del camp d'observació, i s'entenia, i s'entén encara, que només quan s'elimina la subjectivitat s'està realment fent ciència (Claval, 1991).

Així, l'ideal positivista va ser establir distància entre investigador i objecte investigat, afavorint la despersonalització per incrementar una suposada objectivitat. La narrativa biogràfica precisament nega aquest supòsit, ja que els informants parlen d'ells mateixos, sense silenciar la seva subjectivitat, i això fa que en l'actualitat tinguem el repte de construir noves metàfores que ens permetin reubicar-nos com a coconstructors de les realitats de les que formem part i que, alhora, pretenem modificar (Anderson, 1999).

El progressiu esgotament del positivisme i la rehabilitació, per exemple, de l'hermenèutica com manera pròpia de coneixement en ciències socials i humanes, ha canviat el panorama. El filòsof Wilhelm Dilthey, va contribuir decisivament a començaments del segle XX a donar un estatut epistemològic propi a les ciències humanes, situant les relacions personals viscudes per cada individu com a clau de la interpretació hermenèutica. Aquestes experiències viscudes són la base de la comprensió de les accions humanes. En aquest sentit Ortega y Gasset (1966), assenyalava en el seu assaig Història com a sistema que enfront de la raó pura físic-matemàtica hi ha una raó narrativa. Per comprendre una mica quelcom humà, personal $o$ col·lectiu es fa necessari explicar una història.

En els anys trenta del segle passat, Edmund Husserl (1859-1938) va desenvolupar una anàlisi de com la ciència de la modernitat (Galileu-Descartes) va excloure el món de la vida, fent una abstracció dels subjectes sense tenir en compte que són persones amb una vida personal. Molts dels problemes que portem en la nostra tasca docent per encaixar la investigació-aprenentatge narratiu en la investigació tradicional provenen d'aquesta separació que va introduir la ciència moderna. En aquest sentit Husserl (1990) assenyala que aquesta exclusió no està justificada en tant que el món objectiu-científic es fonamenta en el món de la vida, base de tota evidència.

D'acord amb aquests plantejaments, la perspectiva narrativa i biogràfica està adquirint cada dia més rellevància. D'alguna manera reclama el seu lloc en el paradigma qualitatiu convencional, i sense limitarse a ser una metodologia de recol·lecció $i$ anàlisi de dades altera alguns supòsits $i$ modes assentats d'investigar en l'àmbit humanístic i social.

D'aquesta manera la investigació biogràfica i narrativa en educació és distància del contrast establert entre objectivitat i subjectivitat. Com a forma de coneixement, el relat capta la riquesa i la poètica dels significats de qüestions humanes elementals (emocions, desitjos, carències...) que no poden ser expressats en definicions, arguments o proposicions abstractes, com fa el raonament lògic-formal.

A partir d'aquestes premisses triangulem la nostra forma d'ensenyar (educere) tenint en compte el comportament (coneixements pràctics), l'experimentació (l'acció-participació-reflexió) i la pròpia cultura personal (l'experiència biogràfica). En la integració d'aquestes bases es fonamenta la base epistemològica que guia la nostra acció com a docents. A través de models teòrics com el construccionisme i la 
deconstrucció cientifico-filosòfica, l'anàlisi de la conversa i el discurs, i les perspectives de pensament ecològiques i de complexitat explorem i dotem de contingut la nostra acció docent. Així, com hem dit, des de les nostres perspectives pensem la docència també com un espai epistemològic que ens permet coconstruir narratives alternatives a les associades a la cultura moderna per tal de donar resposta, o com a mínim intentar-ho, a les principals problemàtiques de la nostra època (Foucault, 1968).

Per això, hem proposat una renovació de l'organització interna de la docència i els mètodes de treball per tal d'afavorir que els estudiants i els professors es trobin en situacions noves que requereixin un compromís personal. Per exemple, Maturana (2003) planteja que hem de treballar amb els estudiants, com a membres d'un taller renaixentista... com un lloc on l'estudiant ve a fer i a reflexionar sobre el seu quefer i ésser, un lloc on el professor no realitza afirmacions definitives i objectives, perquè una afirmació d'aquest tipus és com una petició d'obediència. Aspirem al fet que els estudiants siguin capaços de fer qualsevol cosa, però sent responsables del que fan, i això exigeix que siguin capaços de reflexionar sobre el seu quefer.

Entenent que reflexionar reclama "deixar anar" el que es posseeix per posar-ho en l'univers de les emocions i observar-ho; convidem a l'estudiant a què no tingui por de deixar anar allò que posseeix, perquè si no ho deixa anar no podrà veure-ho i per tant mai podrà reflexionar sobre el que té. Del que es tracta és d'assumir una actitud de deixar el que s'atresora per observar-ho, si no és així, serà difícil ser responsables de les accions que es realitzen perquè es buscaran justificacions fora del jo. El repte docent, perquè això sigui possible, és "estar" present en els seus actes, perquè el que construïm a l'acadèmia és un món amb l'altre, amb l'estudiant, i el món que construeixo amb l'altre. "El descubrimiento del otro pasa forzosamente por el descubrimiento de uno mismo" (Delors, 1996, p.5)

\section{L'autobiografia com a forma de (re)coneixement i (re)construcció d'identitat(s) en la docència}

Per dur a terme aquesta experiència docent des de l'assignatura de Rol i identitat ens hem fixat i recolzat en el denominat mètode biogràfic. En el context de les ciències socials i humanes el mètode biogràfic és una estratègia etnogràfica d'aproximació a l'altre (Pujadas, 1992). Concretament, l'estratègia autobiogràfica respon perfectament a l'enfoc humanístic, interpretatiu i fenomenològic en el que recolzem la nostra mirada epistemològica (Denzin, 1989). Tanmateix, l'edició d'autobiografies és un camp transdiciplinar que abraça diferents especialitats com la sociologia, l'antropologia, la pedagogia, la filosofia o l'art i té nombrosos antecedents en l'àmbit de l'ensenyament i la investigació. En aquest sentit, les narracions autobiogràfiques en l'educació no ens les plantegem com una simple acció didàctica que es basa en l'aplicació d'una sèrie d'activitats a l'aula, sino que tractem de treballar-les des de la seva dimensió epistemològica, semàntica $\mathrm{i}$ estructural per tal d'impulsar a l'estudiant a re-construir el seu propi sistema narratiu basant-se en la conjunció de tres elements bàsics: la memòria, la metàfora i el llenguatge (Olney, 1991). Per tant, l'acció educativa es conceptualitza com un esdeveniment biogràfic, i s'emmarca en la citada Dimensió biogràfica de l'educació (Gil Cantero, 1997, p. 117). Es tracta, doncs, de generar un context experiencial que ja anticipaven autors com Maria Montessori, Ovide Decroly o John Dewey (Vilafranca, 2003).

D'altra banda, tenint en compte que la temàtica de l'assignatura de Rol $i$ identitat gira al voltant de la construcció d'un "jo" en el Treball Social, l'ús de l'autobiografia afavoreix que l'estudiant reflexioni sobre les maneres de conèixer i de ser en el seu context biogràfic, replantejant-se d'aquesta manera els efectes en la seva "identitat". En aquest procés la subjectivitat esdevé també una font de coneixement, d'interpretació de la realitat i de canvi per els estudiants.

Per contextualitzar breument el marc sociohistòric en el que l'autobiografia es constitueix com expressió d'identitat des de la seva dimensió narrativa i ètica, apuntem que les formes autoreferencials com diaris, històries de vida, biografies, cartes, etc... centrats en la presentació del "jo" prenen cos en el procés de 
modernització de la societat amb la constitució del primer capitalisme fordista i el naixement de l'esperit burgès. En certa manera, l'exaltació de la personalitat esdevé per artistes i escriptors una manera de "rebel-lar-se" davant d'un ordre cultural que paradoxalment promou el sentit d'individualitat, fent saltar el sí mateix a la zona de l'espai públic. Així, començant per Rousseau (1925) amb les seves memòries Les Confessions al segle XVIII, passant pel romanticisme del segle XIX amb Baudelaire, Rimbaud, Mallarmé, etc, fins contemporanis del segle XX com Virginia Wolf, Proust o Joyce experimenten en els seus relats la intimitat de seu ésser. A través d'aquestes veus autoreferencials sorgeixen els gèneres canònics com l'autobiografia, les memòries, diaris, escrits epistolars... que donen l'oportunitat de canalitzar l'energia interna del subjecte i d'expressar públicament la seva sensibilitat d'una manera genuïna. Aquesta sensibilitat brillava especialment quan s'expressaven caràcters de contingut íntim amb sentiment, imaginació, o intuïció.

Actualment, el nostre context contemporani (occidental) caracteritzat per la immediatesa, el consum i la hiperconnexió tecnològica s'encarrega de fondre -i confondre- la nostra identitat volguda amb la disparitat de referències imposades (propagandístiques, visuals, culturals ...) que pren el subjecte per definir la seva naturalesa. Així, el miratge d'una identitat fixe i estable pròpia de la societat moderna deixa pas a models identitaris estandarditzats, efímers i reciclables vinculats normalment als interessos del mercat. Per exemple, Les noves tecnologies, la comunicació global i superficial (exprés) generen noves formes autobiogràfiques (webs, plataformes i espais virtuals 2.0, reality shows, relats mediàtics...) que es configuren a partir d'elements que també són ficcionals desdibuixant així al propi subjecte. Així, és en l'anomenat espai biogràfic, en termes d'Arfuch (2007), on es manifesta el subjecte contemporani en nombroses variants autoreferencials i biogràfiques que poden anar des de quaderns de notes, entrevistes, records, etc... fins a vídeos o formes artístiques objectuals. Aquestes expressions autobiogràfiques pròpies de la nostra contemporaneïtat situen el subjecte en una narració constant d'un mateix, re-elaborant constantment el procés identitari a partir de la diferenciació en relació a l'altre.

Tenint en compte aquest marc, diríem postmodern... el nostre interès es focalitza en repensar biogràficament el jo com un producte de la reflexió i el pensament, allunyant-lo de les tècniques confessionals, que insten al subjecte a parlar constantment com si fos un examen de si mateix, i passar a col·locar el subjecte en el lloc d'un narrador que parla des de si mateix. D'aquesta manera podem entendre que el subjecte autobiogràfic regula aquest dinamisme reflexiu i dona sentit a la pròpia experiència per iniciar així una negociació del jo amb la realitat social i amb l'altre.

Així, el marc conceptual i epistemològic que ens aboca a l'ús de l'autobiografia sorgeix d'aquest intent per relacionar i comprendre aquells significats que afecten al subjecte-estudiant narratiu, és a dir aquells significats que desbloquegen la seva biografia i impregnen la seva subjectivitat. Considerem que aquesta relació es manifesta perquè la forma autobiogràfica opera en el límit de la interioritat i l'exterioritat d'allò real. En aquesta acció reflexiva que fa el subjecte-estudiant autobiogràfic quan relata les situacions, moviments i esdeveniments de-construeix l'adherència referencial de la seva història.

El que evoca l'autobiografia des del full en blanc és un lloc on escriure alguna cosa que pren el seu propi camí. El text prendrà, igual que una pintura, la seva vida pròpia. Un espai que possibilita recorreguts a escala d'un mateix generant sentit i significació en la seva pròpia narració, podent incorporar altres sentits a allò pressuposat i ocult en el substrat cultural. Per tant, des d'una perspectiva docent, l'autobiografia se'ns revela com un sistema de co-construcció obert, que fomenta la pregunta mitjançant un mètode de re-visió i que permet gestar una manera de pensar complexa en tant que il-lumina el context de cada moment. Des d'aquesta mirada, si es vol subjectivista i dialògica, entenem que el relat del jo suposa explorar la pròpia intencionalitat, deixant de banda la causa i l'efecte, és a dir la finalitat. Es tractaria doncs d'accedir a aquelles relacions que connecten les adscripcions de sentit que configuren la singularitat de la identitat. 


\section{L'assignatura de Rol i identitat del Treball Social i la metodologia autobiogràfica}

Com hem explicat al començament, fa aproximadament set anys quan es va dissenyar i es va posar en marxa l'assignatura de Rol $i$ identitat del Treball Social, vam assumir el repte de qüestionar les certeses que fins llavors s'havien construit entorn al saber del Treball Social. No es tractava de destruir-les ni invisibilitzar-les... es tractava senzillament que poguéssim crear conjuntament amb els estudiants un espai que permetés deconstruir sabers, camins, mètodes i tècniques que s'havien construït durant més d'un segle i que garantia al Treball Social poder transitar per situacions predictibles i més o menys conegudes, intentant que els models apresos i incorporats funcionessin amb un alt grau d'eficàcia. Aquests models d'ascendència positivista servien per ordenar: estudiar, diagnosticar i intervenir en la "realitat" i que les accions poguessin encaixar amb ella, permetent així fluïdesa en l'experiència i transparència en les nostres relacions amb aquesta realitat. Això, paradoxalment, pot conduir a pensar que quan naveguem per allò conegut, el nostre quefer professional no només esdevé segur sinó també immutable.

En aquest sentit, a l'assignatura de Rol $i$ identitat generem aquest espai que busca alterar els formats clàssics de transmissió del coneixement, un espai biogràfic com hem dit, on predominen discursos, connexions i accions entre els subjectes implicats (estudiants, professors, convidats, experts, etc...). És a dir, en la nostra organització docent ja no es tracta de reconèixer una sèrie de veritats universals que han de ser anunciades i transmeses, sino que mirem d'assumir les potencialitats existents en els estudiants a través de la reflexió biogràfica per deconstruir i reconstruir el sistema de veritats que caracteritza i domina el currículum acadèmic (Ordine, 2013).

Així doncs, tenint en compte l'exposat, en les narratives dels treballs autobiogràfics, concretament en treballs realitzats pels estudiants dels últims tres i quatre cursos, s'aprecia com van incorporant i compenetrant-se amb el coneixement complex. És a dir, hi ha una apertura cap a la pròpia subjectivitat que documenta els seus treballs com a testimonis existencials de creació. Per il·lustrar-ho, anirem mostrant a partir d'aquest punt de l'article algunes trames narratives i valoracions que els estudiants realitzen en els seus treballs.

En relació a l'exposició de textos dels estudiants cal advertir d'algunes consideracions. En primer lloc, en tots els fragments de treballs mostrats en aquest document es preserva l'anonimat dels estudiants i tenen el seu consentiment d'ús per finalitats acadèmiques. En segon lloc, per tal de facilitar la tasca de selecció textos hem estimat adient només extreure'n d'una mostra ${ }^{2}$ intencional de 60 treballs autobiogràfics que corresponen al total d'estudiants matriculats d'un grup del torn del matí de l'assignatura de Rol i identitat del Treball social del curs 2016-17.

Tal i com hem apuntat, la dimensió biogràfica i epistemològica que caracteritza l'assignatura ens situa en un context de construcció col-lectiva i heteràrquica on el coneixement es compartit i construït entre el professor i l'estudiant. Aquesta experiència d'aprenentatge ha permès estimular en els estudiants la participació i l'acció crítica (com a subjectes proactius), i alhora potenciar una actitud més executiva, és a dir, com un aprendre a crear (Marina, 2012).

Yo no me considero normal, normal es un programa de lavadora. Yo soy autodestructiva, porque todo cuanto veo me cautiva o me limita. Em resulta complicat trobar el meu lloc. Me indigno a jornada completa, 24/7, aunque no me paguen por ello. A veces me abro en canal y me brotan poemas (o dibujos) de las entrañas. También traduzco porque las lenguas son casas y a mí me

\footnotetext{
${ }^{2}$ Tot i que la mostra triada per la valoració qualitativa de l'activitat consta de 60 treballs d'un grup del torn de matí del curs 201617 , fem constar que per analitzar el procés transformatiu que va de l'heteronomia a l'autonomia en l'adquisició del coneixement dels estudiants hem tingut en compte l'evolució i els canvis que s'anaven produint al llarg d'aquests quatre cursos en els que s'ha utilitzat el mètode autobiogràfic. Per tant, en termes quantitatius, com a equip docent, hem tingut en compte més de 900 treballs autobiogràfics al llarg d'aquests quatre cursos que comprenen el grups de matí i els de tarda.
} 
gustan mucho las visitas. Mi desorden está ordenado. Querer ordenar mi desorden significaría desordenarlo todo. (Estefanía, 2017)

En l'aspiració d'una formació democratitzadora que busca l'autonomia del subjecte, en tant que pren consciencia d'un coneixement basat en la pràctica i la reflexió, hem potenciat aquelles línies pedagògiques en les que la formació esdevé una activitat de reflexió amb l'objectiu d'actuar sobre aquelles situacions que dificulten l'emancipació del subjecte.

No obstant gràcies als tres primers seminaris realitzats dins del marc de l'assignatura, he comprès com el fet de narrar la vida, i la necessitat que tenim de fer-ho, està relacionada amb molts aspectes, però sobretot amb la tant mencionada idea de 'caos'. Des del meu punt de vista, considero que narrar una part de la meva història, no només m'ajuda a materialitzar-la com es comentava anteriorment, sinó que també em suposa buscar conscient o inconscientment respostes per mitjà de la reflexió (Paula, 2017)

Per dir-ho d'una altra manera, en aquesta activitat del conèixer, procurem donar resposta als reptes que ens presenta un context socio-polític hegemònic, a la complexitat i a l'acumulació excessiva dels sabers tecnocientífics. Especialment en un grau com el de Treball Social ens sembla indispensable anar una mica més enllà de la mecanització del coneixement de la vida humana que han desenvolupat les ciències socials $\mathrm{i}$ de la psique en el context de la modernitat. La formació en la complexitat, per tant, suposa impulsar un pensament lligat a la pràctica $i$ als problemes derivats de l'experiència humana; problemes que els futurs treballadors socials hauran d'afrontar $\mathrm{i}$ comprendre des d'una intel-ligència multidimensional $\mathrm{i}$ transdisciplinar (Morin, 2003). El pensament reflexiu també revaloritza el paper de l'estudiant en la construcció del coneixement, és a dir, més enllà de dir quelcom és així o està així, l'estudiant pot interrogarse sobre aquesta realitat a priori immutable i prendre com a punt de partida aquelles esquerdes que descobreix en les racionalitats que legislen sobre la veritat.

La etapa de la universidad ha sido muy significativa para ella, le ha despertado el pensamiento crítico. Hasta el momento nunca se había cuestionado casi nada de lo que sucedía en el mundo. Asentía con la cabeza como la mayoría de personas que coexisten en la sociedad, pero el encontrarse con espacios de reflexión, de crítica, de visibilización de otras realidades ha podido comprender que no todo es como nos lo venden. Al final, 'la práctica de uno consigo mismo: va desde la ignorancia a la crítica. La instrucción es la armadura del individuo frente a los acontecimientos (Foucault, 1987, p.54)'. Este transcurso de tiempo ha significado en su mirada y en su pensar un giro de $360^{\circ}$; esto ha sido gracias aquellos profesores que le han hecho cuestionarse todo lo que le envuelve. Hasta el punto de preguntarse si realmente había estudiado Trabajo Social por vocación o por las influencias del entorno. Al final entendió que nadie es libre de pensamiento, que todos y cada uno de los que vivimos en el mundo estamos condicionados, pero la libertad emerge en el momento en el que somos conscientes de nuestra propia ignorancia. (Sara, 2017)

D'aquesta manera podem formar individus creatius, individus que transformen una mirada que busca certeses per acceptar ara la incertesa i el caos en la construcció del coneixement. No tractem d'establir apriorísticament les característiques d'una pretesa essència humana immutable, intentem elaborar una reflexió sobre l'esser humà en la seva globalitat, capaç d'explicar com aquest ésser humà és la condició i la possibilitat de les ciències i, en general, de la conducta humana: llenguatge, producció, religió, mites, acció moral, agressivitat...

D'altra banda, el recurs narratiu i biogràfic que hem fet servir, en aquest cas en la formació dels treballadors/es socials, com hem vist, se'ns ha presentat com una oportunitat per explorar altres sistemes de coneixement més enllà de les posicions realistes i positivistes. L'ús de l'espai biogràfic (Arfuch, 2007) és en el nostre cas una decisió ontològica i epistemològica que ens ha permès introduir a l'estudiant en la comprensió del jo, la regularització de la subjectivitat i el desmembrament d'allò que diem identitat. Concretament, la forma autobiogràfica (contemporània) ens ha facilitat que el subjecte-estudiant hagi 
reconegut com ha anat incorporant i transformant el propi saber i coneixement, i contemplar-se així a ell mateix des de la singularitat.

Estem gairebé forçats a definir la identitat, sobretot a l'àmbit professional, qüestió que respon a una era de la classificació, doncs mentre puguem identificar, podrem tractar a les classificacions uniformement. Però depèn de la posició un tingui, de l'experiència, de les relacions, dels sabers... és com posteriorment aplicarà la seva professió. Amb el temps m'he adonat que treball social també és una postura davant de la vida que traspassa lo purament acadèmic. L'objectiu principal d'iniciar el grau en treball social era el d'obtenir un sou amb una feina que aparentment m'atreia, però ara a un mes de finalitzar el grau es compagina amb molts d'altres com ara el d'APRENDRE a viure, un procés que mai s'acaba. (Clàudia, 2017)

Hem pogut observar que l'experiència del subjecte-estudiant, i concretament la narració que en fa d'aquesta, presenta un coneixement local que acostuma a ser més genuí i proper a la complexitat de les situacions i problemes que ens planteja la vida. En aquest sentit, a més, en el context del grau de Treball Social observem que aquesta experiència biogràfica es presenta també com un instrument coherent $\mathrm{i}$ útil per l'anàlisi de la realitat social i la comunicació dialògica que els/les futures treballadores socials necessiten per la seva pràctica professional.

La psicología positiva, y que en la cuestión del cáncer ha hecho muchos estragos, hace alusión a que debemos olvidar lo negativo, lo doloroso y luchar la batalla. Pero a mí me dolió que en ese momento en el que acababa de perder a mi abuelo al que adoraba, y mi madre estaba enferma me dijesen que tocaba sonreír, pues no, no podía. Solo podía llorar, y me hacía sentir mal que me dijesen que tenía que hacerlo por mi madre. Por ello, valoro tantísimo el respetar el ritmo de las personas, a veces no aguantamos el lloro de otro por miedo a uno mismo, y con ello evitamos hablar de dolor, de sufrimiento, de malestar. Queremos saltarnos ese paso e ir directamente a ese supuesto empoderamiento. (Lorena, 2017)

L'espai i el temps (auto)biogràfic en aquest procés d'aprenentatge és, per tant, un espai d'encreuament narratiu entre allò públic i allò privat que afavoreix la discontinuïtat de l'organització educativa convencional ja que permet al subjecte-estudiant reapropiar-se dels seus propis coneixements i també reconfigurar el seu paper en l'aprenentatge. El subjecte-estudiant, en aquest sentit, pren part en el seu propi procés d'aprenentatge, i ho fa, des del punt de vista autobiogràfic, construint la seva pròpia realitat.

Los límites de mi mundo venían marcados por mi lenguaje. Mi vida no era una novela romántica. Yo no era una princesa de cuento. Yo era una chica de 18 años con pensamientos propios, claros y definidos. Yo era lo mejor de mí. Yo estaba perdida, yo me iba a encontrar. La belleza oculta es una pel·lícula que vi hace relativamente poco. Según esta el AMOR, el TIEMPO y la MUERTE están conectados y son los tres pilares básicos de la vida. Creo en esa afirmación. En la película a pesar de lo malo de las situaciones, hay algo de belleza en ellas, solo tienes que saber mirar. (Paula, 2017)

Per tant, en el procés de relat autobiogràfic l'estudiant construeix un espai (propi i compartit), és a dir un espai d'aparició a l'esfera pública (Arendt, 2005) que re-connecta i visibilitza les diferències i les singularitats dels diferents discursos. Aquest procés, íntim i de rememoració del passat, també es vincula a l'expressió d'un valor estètic i ètic de la vida, en tant que aquesta es conforma pel conjunt d'accions pràctiques que compartim i definim. Cada narració, cada enunciat (pensaments, sentiments, records, idees...) significa doncs una forma d'existència $i$ una forma creadora de coneixement $i$ saviesa que ens ensenya (i teoritza) que a través de l'altre ens reconeixem a nosaltres mateixos.

Me digo muchas veces que, como especie, el hecho de razonar nos obliga a tener casi una obligación intrínseca en reflexionar, a cuestionarnos que puedo hacer yo por mí y por los demás. Siento que el haber vivido esta experiencia casi me obliga a lanzar un grito al mundo y decir: 'Alto, 
hay personas que no se encuentran, que no saben, que no comprenden que hacen aquí y estas personas podrían sentirse mejor con una simple mano amiga, alguien que les escuche y entienda, no alguien que les pretenda cambiar'. Por eso creo que estoy haciendo TS. Sin pensarlo te diría que para ayudar a los demás, pero esa sensación o pensamiento no la recuerdo realmente. Sin embargo, sí que recuerdo lo que es no sentirme parte de, ser 'la otra', la enferma, la que no puede y no me gustó nada el papel que me obligaron a vivir. Hubiese sido bastante sencillo no haberme sentido tan mal conmigo misma, si me hubieran visto como un todo, no como una parte a arreglar. (Marta, 2017)

Com es pot observar en els fragments presentats, el subjecte-estudiant s'autoreconeix en els elements singulars que configuren la seva història aproximant-se a la comprensió de la complexitat. És a dir, en el relat articula una intencionalitat sobre la figura narrada propiciant una obertura en el sistema complex de constitució del subjecte que dificulta plasmar una significació clara del jo:

La pregunta seria llavors: qui sóc per mi? Potser estic massa cansada per preguntar-m'ho. Qui sóc quan el punt de referència des del qual em defineixo sóc jo mateixa? Puc preguntar qui sóc, sent jo el subjecte i l'objecte? Puc fer una pregunta on pregunto sobre el preguntador? Podien fer-ho els filòsofs quan volien definir la bestia i el sobirà, sent ells mateixos el sobirà? Puc tenir una resposta? (Ariadna, 2017)

En aquest context o espai (auto)biogràfic es configura un sistema tropològic i metafòric que construeix i (re)construeix un "rostre". Això vol dir que la subjectivitat està en constant transformació ja que el subjecte-estudiant caracteritzat com a narrador, autor i protagonista es cobreix la cara amb la màscara d'un dels seus personatges. Podem dir que el subjecte-estudiant-autor re-crea constantment la seva existència quan es converteix en narrador des de si mateix allunyant-se així de la seva mateixa autoria.

Es pot narrar la vida d'una persona? Arrel de plantejar-me aquesta pregunta, vaig entendre, d'una banda i gràcies a la bibliografia corresponent a l'assignatura que el relat que explicaré està definit per diversos 'jo' que entren en acció en diferents moments, i que per tant poden narrar diversos elements que poden compartir o no punts de vista. El primer i com és natural és la meva posició com autora del relat (jo autora), en el sentit que a través del llenguatge i la construcció de paraules, no només dono ordre a les meves experiències sinó que amb la redacció del document, materialitzo en certa mesura part de la meva història i li atribueixo sentit. En un segon terme el relat està influenciat pel paper que puc desenvolupar com a narradora dels fets. Aquest jo com a narradora considero en primer lloc, que es omniscient, ja que l'exposició recau en primera persona i per tant, sóc conscient dels pensament i sentiments que desenvolupo com a "jo personatge". En segon lloc però, penso que em serveix per diferenciar a l'hora de desenvolupar la història, la meva vida viscuda de la narrada i per tant té una influència directa en el meu punt de vista. (Paula, 2017)

La redacció d'aquests textos deriva d'un treball autobiogràfic que realitzen els estudiants durant el període en el que cursen l'assignatura i que finalment és la principal evidència que fem servir els professors per avaluar. Aquest treball té en compte diferents variables conceptuals i elements teòrics que evidentment es van treballant i reflexionant durant el curs i acaben incorporant-se en el treball adequant-se a la pròpia narrativa de l'estudiant. Considerem oportú, per tant, presentar també en aquest text les variables sobre les que es fonamenta la construcció d'aquests relats autobiogràfics que giren al voltant de la construcció d'un "jo" treballador/a social.

En cada fragment mostrem diferents moments i formes biogràfiques que estan relacionades amb els elements d'anàlisi narratiu que es tenen en compte en la configuració i valoració dels treballs.

En el primer fragment exposem una presentació i/o introducció del treball autobiogràfic.

Directamente sacado del horno: no pretendo hacer disfrutar al lector ni tampoco realizar una autobiografía con la que vaya a disfrutar yo mismo. El único motivo por el que se está escribiendo 
cada una de las palabras es plenamente académico. Sin embargo, el enfoque es libre, y dentro de esa libertad establecida (valga la contradicción) la utilidad queda servida a la merced del caos. No esperen orden. Lo que se lea hoy no será fijo, no será estático, no nos servirá para el día siguiente ni tampoco de por vida, únicamente escribirán mis diferentes "yo" según como recuerde lo que escribo y según lo que quiera relacionar ese día con la disciplina de Trabajo social y mi vida. Y con lector me refiero tanto a aquel que tenga la fortuna o la mala suerte de llegar a leer esto, tanto igual que el que lo está escribiendo. A este segundo la advertencia es doble, no te eches atrás con lo que has escrito. Esto que lees/escribes amigo mío es lo que soy, lo que somos y lo que serás el día que lo leas. Será un tu interpretado por lo que lleves a la espalda. (Pedro, 2017)

En el segon fragment s'hi plasmen elements d'explicació i reflexió sobre la presa de decisions.

Retornant a la primera infància, un cop finalitzada l'etapa a l'escola bressol, els pares orientats per una tutora de la mateixa, hem van inscriure en una escola concertada. Era una escola que formava part del Col·lectiu d'Escoles per l'Escola Pública Catalana (CEPEPC). Una organització creada durant la transició espanyola per unes 80 escoles catalanes creades com a cooperatives de pares 0 de mestres. L'escola era laica, progressista i activa, per tant s'adequava a la ideologia dels pares i en certa mesura són elements que han influenciat els meus propis valors i ideari laic i progressista. Per als pares era important el fet de que es tractés d'una escola que promovia aquests valors o idearis, sovint a casa escoltava com argumentaven les barbaries produïdes al llarg de la història promogudes per aquelles persones que orientades per uns ideals es consideraven en possessió de la única veritat absoluta i per tant la imposaven a la resta. Compartien la idea que assenyala Ordine (2013), quan indica que sense la negació de la veritat absoluta no hi pot haver espai per a la tolerància, no hi ha cabuda per al diàleg. (Clàudia, 2017)

En el tercer fragment l'estudiant assenyala o selecciona moments d'autorepresentació en la construcció del jo (treballador/a social)

Obviamente, el hecho de estar vinculada a una familia católica, la incitó a estar vinculada a esta institución religiosa, incluso a llegar a creer firmemente en la palabra de Dios. Aquí es donde ella relaciona su vocación, con la relación que estableció con la Iglesia. Ya que esta siempre ha estado vinculada a la caridad de los pobres, a trabajar con gente vulnerable y en exclusión. En definitiva, las Iglesias siempre han sido entidades de beneficencia. Lo cual fue seguramente uno de los puntos de inflexión dónde encontró cuál era su verdadera vocación, ayudar a los demás. Pero ¿qué es ayudar?, como bien sabemos entre seres humanos se establecen relaciones utilitarias, todos nos utilizamos, no existe el altruismo, creía que era por los demás. Sin embargo, es por nuestro egoísmo intrínseco, ayudar a los demás significa dar algo para yo tener una consciencia más tranquila, para sentirme mejor y, sobre todo, para reafirmar mi posición en la sociedad (Ksarz, 2004). Además, cuando Sara ayuda, no es consciente de que su acción es un mero asistencialismo, así nació el Trabajo Social. (Sara, 2017)

Al quart fragment l'estudiant reflecteix els canvis externs relacionats amb transformacions i processos evolutius i històrics de la societat vinculats a les estructures de poder polític, econòmic, i social. És a dir, posa en relació la narrativa amb el canvis socials d'ordre general (polítics, econòmics, sobre el coneixement, tecnològics, etc.)

He crescut en un context de crisi econòmica, el meu pare n'ha patit les conseqüències, la crisi ha paralitzat a la gent gran per la por de que les coses ja no siguin com abans. Però avui, sobretot els joves, estem acostumant-nos a un temps veloç, a que les coses no durin gaire, a que apareguin noves oportunitats que devaluaran les existents en tots els aspectes de la vida, des dels objectes materials fins a les relacions amb la gent $\mathrm{i}$ la pròpia relació que tenim amb nosaltres mateixos: Com m'avaluo? Quina imatge tinc de la meva persona? Quina ambició pretenc que em guiï?, realitzant aquest relat, me n'adono que tot canvia d'un moment a l'altre, estic modificant qüestions 
que havia argumentat en un primer redactat del relat, he considerat altres qüestions rellevants configuradores de la meva identitat, sóc conscient, ara que hi reflexiono, que s'ha anat modificant des de la infància, l'adolescència... (Clàudia, 2017)

Al cinquè fragment l'estudiant analitza i reflecteix els canvis interns, aquells referits a les transformacions físiques, biològiques i d'interacció amb l'entorn.

Empecé a intentar proyectar como me sentía, como quería que me vieran; con juicio propio, decidida incluso rebelde por qué no, rebelde de este sistema que hasta ese entonces no me había traído más que disgustos pero que a la vez, aunque me sintiera rechazada por él, por la sociedad en general, seguía formando parte de esta y es que como bien explica Derrida (2002): 'El hombre no es solo un animal sociable, sino un animal que no puede aislarse sino en sociedad' (p. 50). Así que me hice rastas y adopté una vestimenta más ancha. Me sentía enfrentada al mundo, enfrentada con mi mundo. Para Ordine (2013): 'El enemigo real es el que intenta modelar el espíritu humano de tal manera que ya no se atreva a desplegar sus alas' (p.163) y yo sentía precisamente eso cuando miraba mi entorno. (Marta, 2017)

Finalment els següents fragments mostren com els estudiants construeixen categories pròpies d'anàlisi a partir del relat. És a dir, com situen des d'una perspectiva reflexiva i complexa la construcció del saber (acadèmic, quotidià, formal, etc...) i elaboren reflexions sobre el coneixement per posar-lo en relació al Treball Social.

Concluir la reflexión aportando un último apunte, y es la sociabilidad del ser humano en la toma de decisiones y la definición de 'libertad'. Muchos autores defienden al ser humano como ser social, y en relación a la toma de decisiones entran palabras como 'justicia social' o 'valores sociales', presentes en el Trabajo Social. Es probable que el paradigma que reine en los profesionales sea el de 'consecuencia del sistema', sin pensar quizás en la paradoja de que trabajamos con contextos ' $\mathrm{X}$ ' y personas descontextualizadas. Vivir fuera de un contexto no es imposible, y el cuestionamiento de la libertad es difícil de contextualizar en una profesión tan enmarcada (Pedro, 2017)

De todo lo experimentado y aprendido a lo largo de la carrera, me atrevo a decir que no podemos limitarnos a definir nuestra profesión como algunos hacen, equiparándola como un instrumento, puesto que esto no hace otra cosa que reducir nuestra identidad a la cabeza de lo técnico y se nos da un papel obsoleto, el de solucionadores de problemas. Y yo me planteo ¿Por qué el trabajador o trabajadora social tiene que solucionar los problemas de las personas? ¿Es que si no soluciona no está cumpliendo con su tarea profesional? (Jesús, 2017)

Per últim tal i com es mostra en el relat vull anar cap a un treball social que camini en la corda fluixa on tots els possibles rols que pugui desenvolupar en un futur no siguin estàtics sinó diversos i diferents entre ells i entendre la disciplina des de la vessant humanista i no ser externa a la naturalesa de les situacions ni al paper que desenvoluparia com a professional. Per tant, la resposta a la pregunta sobre si com a futura treballadora social estaria disposada a canviar, la resposta es afirmativa. I ho és perquè mitjançant el relat he hagut de tornar sobre els meus passos, qüestionarlos, reafirmar-lo o refutar-los però sobretot perquè el llenguatge i les construccions socials que he dibuixat en aquest anàlisi no són més que una interpretació sobre la generació d'unes idees que sorgeixen de la incertesa i el caos. Però en cap cas, com s'ha pogut comprovar, és útil per plasmar la dicotomia causa-efecte, la qual cosa m'ha permès per una altra banda construir els meus conceptes propis a partir de la meva biografia (Paula, 2017) 


\section{Valoracions finals}

Quan emprem la metodologia (auto)biogràfica en l'assignatura de Rol i identitat del Treball Social, ho fem des d'una mirada ontològica de caràcter narrativa i simbòlica, és a dir, per nosaltres l'autobiografia, a més de ser una metodologia formativa i/o didàctica, és l'espai on l'estudiant aprèn a construir realitat. Observem que en el transcurs de l'assignatura i després en la construcció dels relats, pels estudiants treballar des de l'autobiografia suposa un (re)coneixement com a subjectes. Concretament, com a futurs professionals del Treball Social (re)signifiquen la comprensió de l'altre atenent el seu context i la seva singularitat. D'altra banda, el treball autobiogràfic en el marc d'una assignatura de quart curs, paradoxalment, enlloc de suposar un punt i final o un recull d'aprenentatges... reobre qüestions, dubtes i interrogants tot iniciant un nou desplaçament en les seves certeses. El seu relat autobiogràfic serà el mapa sobre el que construir un nou recorregut vital un cop acabat el Grau, un mapa pensat i dissenyat per elles i ells, sense imposicions teorètiques del professor o de l'acadèmia.

En relació a la vinculació d'aquesta experiència d'aprenentatge i docència amb el projecte esmentat d'innovació docent Estratègies narratives per afavorir l'aprenentatge del pensament complex (2015PIDUB/046) del grup Transnet, cal mencionar que ha afavorit que els processos de reflexió sobre la nostra pràctica docent fossin més crítics, enriquidors, i evidentment pensats des d'una lògica transversal, tenint en compte els objectius d'altres assignatures del Grau de Treball Social. La vinculació d'aquesta experiència d'aprenentatge i docència amb el projecte esmentat ens ha permès iniciar col·laboracions amb altres assignatures del mateix Grau que han incorporat el mètode (auto)biogràfic en els seus processos d'avaluació i aprenentatge, ampliant d'aquesta manera la nostra iniciativa a altres assignatures. Els dos primers anys de l'inici del projecte (octubre de l'any 2015), teníem implicades un total de quatre assignatures del Grau de Treball Social: Epistemologia del Treball Social de primer curs, Habilitats Socials i comunicatives de segon curs, Política Social i societats en transformació de tercer curs i Rol i identitat de quart curs. D'aquestes assignatures finalment ha sigut Epistemologia del Treball Social la que ha incorporat com a metodologia docent l'autobiografia en el seu programa. Tanmateix no ha estat possible establir vincles comparatius entre aquestes experiències per factors aliens al disseny del projecte. La manca d'equips docents estables en aquestes assignatures no ha facilitat el seguiment d'aquests projectes de llarga durada.

Aquest treball respon així a l'encreuament vital d'un grup de professors, dones i homes, que fa ja uns anys va començar a escoltar-se, a interrogar-se, a dubtar. En el turó de Mundet va ser l'espai des d'on parlàvem dels nostres somnis, dels nostres fills, els nascuts i els que han de néixer, de les nostres alegries i tristeses, del Treball Social, dels sabers i els no sabers.

Observant el Mediterrani ens vam anar interpel lant, posant en marxa projectes, canviant alguns programes d'assignatures, escatint sobre ètica i estètica, sobre ciència i art, sobre positivisme i subjectivisme, sobre les raons de les nostres emocions, en definitiva al llarg d'aquests anys hem intentat construir ponts i passeres a un conjunt complex d'aprenentatges oriünds dels nostres processos biogràfics. Ens vam anar traient les màscares per intentar arribar al saber quotidià, d'allò que ens humanitza, de saber que no sabem. El nostre desig es ser artesans de contextos d'aprenentatges.

\section{Referències}

Anderson, H. (1999) Conversación, lenguaje y posibilidades :un enfoque postmoderno de la terapia. Biblioteca de psicología y psicoanálisis. Amorrortu, Buenos Aires.

Arendt, H. (2005) La condición humana. Paidós Surcos, Barcelona.

Arfuch, L. (2007) El espacio biográfico. Dilemas de la subjetividad contemporánea. (2ªd.). Fondo de Cultura Económica, Buenos Aires. 
Claval, P. (1991) Els mites fundadors de les ciències socials. Herder, Barcelona.

Delors, J. (1996) Los cuatro pilares de la educación. A: La educación encierra un tesoro. Santillana/UNESCO, Madrid

Denzin, N. (1989) Interpretive Biography. Sage Publications, London.

Foucault, M., Frost, E.C. (1968). Las Palabras y las cosas: una arqueología de las ciencias humanas. Siglo XXI, México, D.F.

Gil Cantero, F. (1997) Educación y narrativa: la práctica de la autobiografía en la educación. Teoría de la educación, 9, pp. 115-136.

Husserl, E., Muñoz, J., Mas, S. (1990) La crisis de las ciencias europeas y la fenomenología transcendental: una introducción a la filosofía fenomenología. Crítica, Barcelona.

Marina, J.A. (2012) La inteligencia ejecutiva. Ariel, Barcelona.

Maturana, H.R. (2003) El sentido de lo humano. J.C. Saez editores, Santiago de Chile.

Morin, E. (2003) Educar en la era planetaria. Gedisa, Barcelona.

Olney, J. (1991) Algunas versiones de la memoria/Algunas versiones del bios: la ontología de la autobiografía. Anthropos, 29, pp. 33-47.

Ordine, N. (2013) La utilitat de l'inútil. Quaderns Crema, Barcelona.

Ortega y Gasset, J. 1883-1955. (1966). Historia como sistema / José Ortega y Gasset. Revista de Occidente, Madrid.

Pujadas, J.J. (1992) El Método biográfico: el uso de las historias de vida en ciencias sociales. Centro de Investigaciones Sociológicas, Madrid.

Rousseau, J.-J. (1925) Las Confesiones. Calpe, Madrid.

Vilafranca, I. (2003) Memòria, relat biogràfic i formació. Temps d'Educació, 28, pp. 13-24. 